\title{
Onycholysis Associated with Enalapril Therapy
}

\author{
Corina Busso MD, Msc. ${ }^{1}$, Rashid Benitez MD. ${ }^{2}$ \\ ${ }^{l}$ Head of the Dermatology Department \\ ${ }^{2}$ Dermatology resident, Hospital Universitario Austral Av. Perón 1500, Derqui, Pilar, Buenos Aires, \\ Argentina (Zip:B1629AHJ)
}

*Corresponding Author: Corina Busso MD, Msc, Head of the Dermatology Department, Hospital Universitario Austral Av. Perón 1500, Derqui, Pilar, Buenos Aires, Argentina

\section{CASE Report}

A 60-year-old female patient consulted in our dermatology department for changes in the fingernails that she noticed 7 days before consultation. This lesions were accompanied by onychodinia that preceded these changes by 1 week. She was in good health and had no history of dermatological diseases such as psoriasis, or systemic conditions such as anemia or hyperthyroidism. She also denied history of trauma, manual work or use of artificial nail tips. For the past 8 weeks she had been taking enalapril 10mg/day for a recent diagnosis of arterial hypertension. She was not receiving any other drug at that time. At physical exam, the third, the fourth and the fifth digits of both hands, showed onycholysis. (Figure 1)

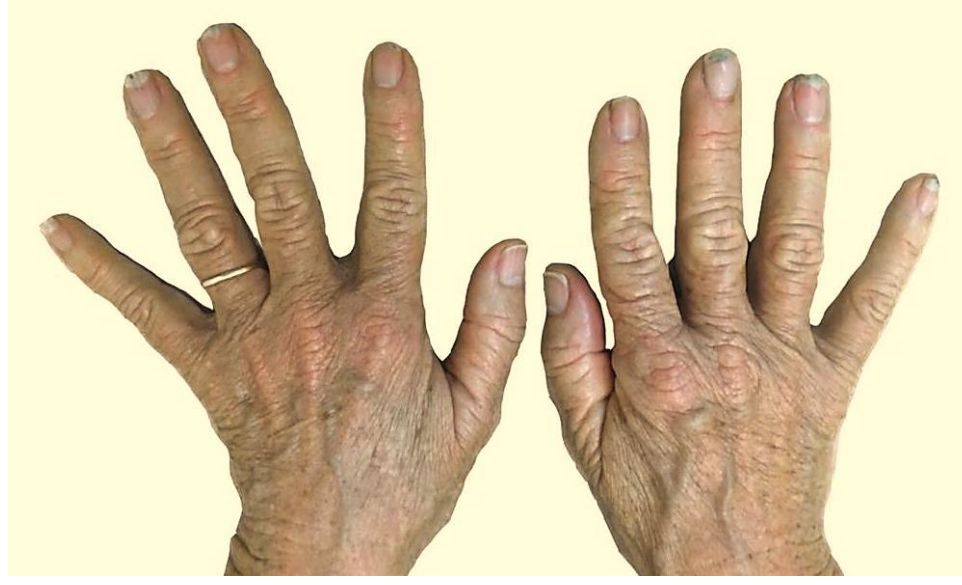

Figure1. Onycholysis on the fourth and fifth digits of both hands. No other nail abnormalities were observed

At that time, it was thought that the nail changes could be a drug-related adverse event, as the temporal association between the start of enalapril and the onycholysis was compatible.
The enalapril was discontinued and switched to losartan. Two months later, the patient was seen in our clinic for follow-up, and her fingernails changes have completely resolved. (Figure 2).

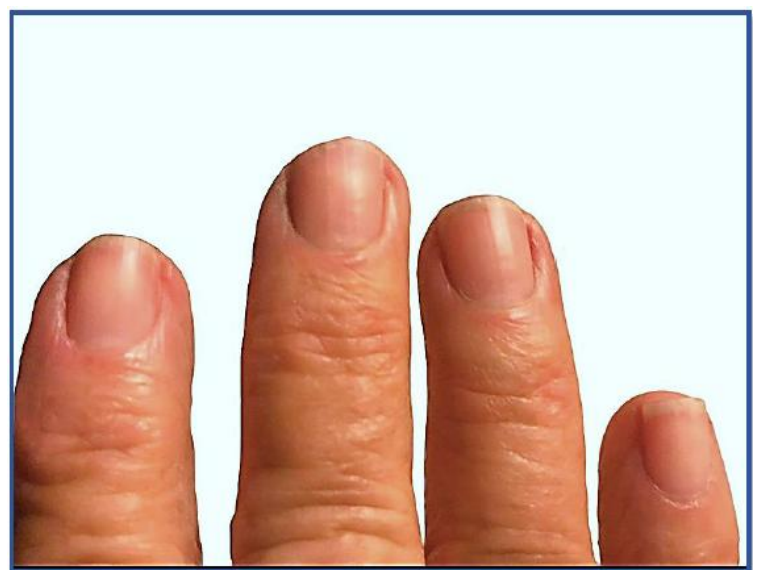

Figure2. Complete resolution of onycholisis after discontinuation of enalapril. 
Onycholysis is the separation of a fingernail or toenail from its nail bed. The most likely cause is trauma, but it can be a sign of skin disease or an infection. It also can be caused by the improper use of manicure tools, or allergic contact dermatitis to nail hardener, adhesives used to attach nail tips, or nail polish remover.

Some medical conditions such as fungal infections, psoriasis, an overactive thyroid gland or iron deficiency can cause the lifting away of the nail from its bed.

Onycholysis also has been associated with a wide range of drugs such as chemotherapeutics (adriamycin, capecitabine, docetaxel, 5-fluorouracil, etoposide, methotrexate, mitoxantrone, paclitaxel, vincristine), EGFR tyrosine kinase inhibitors (erlotinib), tetracyclines, retinoids and sodium valproate.(1)

Angiotensin-converting enzyme inhibitors as captopril have been associated with onycholysis (24) and other cutaneous adverse effects, including photosensitivity, itch, exfoliative dermatitis, pemphigus, and erythematous, macular, papular, lichenoid and pityriasis rosea-Iike rashes. (5)

Onychodynia has been linked with tetracycline and PUVA (6) and may precede onycholysis by 1-4 weeks, as our patient reported.

Enalapril, an ACE inhibitor broadly used to treat arterial hypertension, has not previously been reported associated with nail changes like onycholysis and onychodinia, but the absence of other risk factors, the lack of previous exposure to any of the above- mentioned agents and the temporal association, makes enalapril a highly possible cause of the nail changes that our patient presented.

Up to our knowledge, this is the first report of onycholysis associated with enalapril.

\section{REFERENCES}

[1] Zaiac MN, Walker A. Nail abnormalities associated with systemic pathologies. Clin Dermatol [Internet]. 2013;31(5):627-49. Available from: http://dx.doi.org/ 10.1016/ j.clindermatol.2013.06.018

[2] Piraccini BM, Iorizzo M, Tosti A. Druginduced nail abnormalities. Am J Clin Dermatol. 2003; 4(1):31-7.

[3] Roberts J, Wuerz R. Clinical characteristics of angiotensinconverting enzyme inhibitorinduced angioedema. Ann Emerg Med. 1991; 20:555-8.

[4] Borders J V. Captopril and onycholysis. Ann Intern Med. 1986;105 (2):305-6.

[5] Sabroe R, AK B. Angiotensin-converting enzyme ( ACE ) inhibitors and angio- oedema. Br J Dermatol. 1997; 136:153-8.

[6] Grech V, Vella C. Generalized onycholysis associated with sodium valproate therapy. Eur Neurol. 1999; 42:64-5.

Citation: Corina Busso \& Rashid Benitez, "Onycholysis Associated with Enalapril Therapy", International Journal of Research Studies in Medical and Health Sciences. 2020; 5(4): 01-02.

Copyright: (C) 2020 Corina Busso \& Rashid Benitez, This is an open-access article distributed under the terms of the Creative Commons Attribution License, which permits unrestricted use, distribution, and reproduction in any medium, provided the original author and source are credited. 